\title{
The Use of Computer Models in the Design and Manufacture Machining Attachments in Digital Manufacturing
}

\author{
A.A. Kutin ${ }^{1}$, A.V. Rybakov ${ }^{2}$ and S.S.Ivashin ${ }^{3}$ \\ ${ }^{1}$ Dr.sc.tech., Professor, head of production engineering department Moscow state university of technology "Stankin" Vadkovsky \\ per. 1, Moscow 127994, Russia \\ ${ }^{2} \mathrm{Ph}$.D, Acc.prof. of computer science department Moscow state university of technology "Stankin" Vadkovsky per. 1, Moscow \\ 127994, Russia \\ ${ }^{3}$ Master of engineering Moscow state university of technology "Stankin" Vadkovsky per. 1, Moscow 127994, Russia
}

\begin{abstract}
This article is dedicated to the digital production mold design and manufacturing method based on the controlled interrelated computer models system. The method caters for the quality standards required shorter time lines and reduced efforts for designing complex technical equipment at engineering companies. The research is being financed by the Ministry for Education and Science of the Russian Federation, agreement No. 2664
\end{abstract}

Keywords-computer modeling; digital production; mold; computer-aided design and manufacturing

\section{INTRODUCTION}

The demand for plastic parts has been growing constantly in the structure of the modern mass-market scientific products (cars, smartphone's, etc.) due to the fact that plastics are a universal material in terms of its capabilities and efficiency. With that in mind, major companies push $t$ innovational development and implementation, new design technologies' monetization and usage of plastic items.

Computer-aided design and manufacturing of molds for plastic parts pressure casting as a part of digital production is a top-notch trend for many reasons:

- molds are widely used in modern engineering;

- design and manufacturing take a lot of time;

- molds are constructed in many different ways;

Design and production of shape-generating parts are timeconsuming, although they take advantage of the modern numerical control machines (high-speed processing, electrical discharge machining, 5-axis processing, etc.).

The term "digital production" means multiuser integrated computer system to coordinate and manage all the information, productive resources and functions of the organization. [1].

At different times information technologies for molds design and production were focusing on different aspects: say, technological calculations in 1970s, graphical database design in 1980s, 3D graphical database design in 1990s, computeraided databases and master processes development in $2000 \mathrm{~s}$. As of now, computer-aided molds design and manufacturing aims at using digital prototyping based on the ever-growing set of computer models [2].

Molds design based on information modeling and a set of computer models pre-supposes that all constructional, technological, economic and other information is gathered throughout the whole process of design and manufacturing, including but not limited to assumptions and dependencies, such as plastic part requirements, casting process technology, shape of a mold, equipment, etc. Besides, all the designrelation information is to be available to all project team members within a shared space, similar to the construction term "Building Information Modeling" [3]. Thus, the notion of a "computer model" in this context has broad interpretation, up to the construction model, geometric 2D and 3D models, technological processes and management software for numerical control machines, processes of off-the-shelf parts purchase and delivery management, etc.

\section{TRADITIONAL WAY OF ENGINEERING FACILITIES DESIGN}

Generally, the process of designing and manufacturing molds for plastic pressure casting is iterative [4]. Multiple informational cross-platforms are typical of this process. Both the statement of work and the mold formation can be altered during the implementation based on the outcome of the plastic parts pilot batch production or the results of the whole technical system operation in general. Any change within the design workflow, if there are no traceable relations between the development objects and experts working on them, results into data changes, which means that specific solutions are to be harmonized between each other. Due to the data discrepancies mold performance is considerably worsened, which increases the change-related expenses.

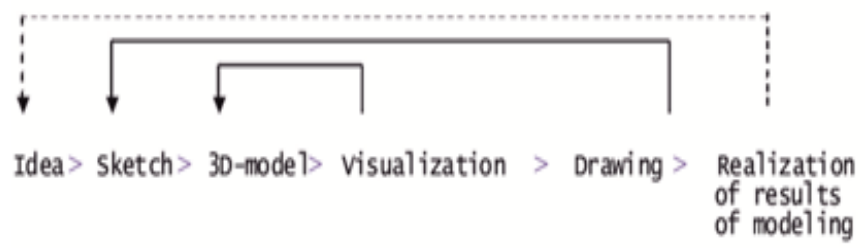

FIGURE I. THE SCHEME OF DESIGNING ON THE BASIS OF METHODS OF COMPUTER MODELING 
Computer-aided modeling has introduced two new objects: a CAD model and a visual modeling result. As of now, the design process follows the workflow outlined in figure 1 .

Being an iterative process, mold formation design combines plastic unit and mold design. Performance of a formed plastic part model, as well as its walls' thickness, are being verified to make sure it is suitable for manufacturing in a mold; slopes needed to extract a casted plastic detail from a mold are formed; parting line to define the plug and matrix formlining is chosen. Normally the libraries of standard parts manufacturers' parametric models are being used for mold form development, while users can complement or modify these ones pursuant to the standards or other technical requirements followed at a specific company. Once a material is chosen, the casting process can be modeled on a formed mold model, which enables an expert to define the time, the mold flow, and the speed of plastic flow, as well as to forecast its parameters, etc. The most consuming part of the process modeling is to define the mold formlining to be processed by numeric control machines.

Nowadays, due to the huge number of discrepant computer models, the following operational scheme is practically adhered to (figure 2).

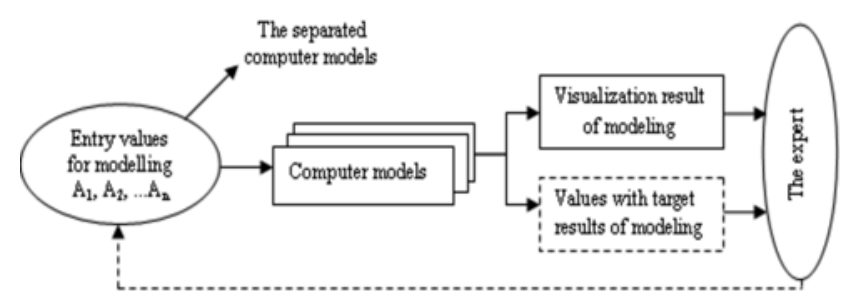

FIGURE II. EXAMPLE OF THE EXISTING SCHEME OF THE ORGANIZATION OF COMPUTER MODELING

These scheme is characterized by the following limitations:

- no integrated subject-matter informational model, that is, no fixed interdependency between a set of different computer models. The relations between different models are only stipulated by a specialist (dashed lines in figure 2).

- no forecasting on how the situation might go during the design and implementation in case any changes are introduced;

- a specialist does not get any information support when designing or developing management programs for mold parts processing;

- best practices are not accumulated and re-used;

- the turnkey software is hardcoded, that is, for any extension you need to turn to the software developer.

The limitations listed can be mitigated by integrating a brand new information and technology environment based on $\mathrm{CAD} / \mathrm{CAE} / \mathrm{CAM} / \mathrm{PDM}$-systems supporting the whole life cycle of the complex plastic part and mold design to be produced within the interrelated computer models' system.

For the sake of integration, all computer models used and the data generated within them are to be unified into a single knowledge base [5].

\section{THE MOLD DESIGN METHOD SUGGESTED}

The authors suggest a new method to further design and manufacture plastic pressure casting molds based on the object-oriented approach pre-supposing an interrelated computer models' system. According to this approach, there are lots of subject-matter objects being interdependent within the mold design and manufacturing life cycle. Each of those objects is modular, polymorphic, encapsulation-defined and abstract. These parameters for engineering design are noted in the electronic knowledge base in a language a subject-matter expert knows. The experience of molds design and manufacturing accumulated at several plants over decades (such as corporate standards, hard copies of the graphics accompanied by relevant descriptions and regulatory references) are formalized and entered into a $\mathrm{CAD} / \mathrm{CAE} / \mathrm{CAM} / \mathrm{PDM}$-system as symbols and graphics. Besides, specialists' workflows are also entered to be re-used by other developers practically.

The reason why object-oriented approach is a good fit for mold design is that, even though many types of molds are used in the production, each of them has specific exquisite objects:

- parts of a mold used to form the shape of a plastic part;

- plate packages;

- mold mounting for the automatic molding machine;

- plate mounting into a single mold form;

- plate steering system;

- gate system for alloy admission into the formation part of the mold;

- plastic details ejection from a mold upon its consolidation;

- pressurized alloy cooling system;

- additional systems (e.g., rod drive mechanisms) and other mechanisms (for complex molds).

Each plastic parts' pressure casting mold has all of the above-mentioned objects in one of the modifications, regardless of whether this mold is designed for plain or complex details (threaded or metal-clad ones), the number of connectors and fracture plane, type of automatic molding machine, etc. Each of those objects has its own design workflow, set of notion, graphic and symbol dependencies. That said, mold design can be put down to designing specific one-of-a-kind parts, that, in turn, are united into a single projects with the design processes contexts and the form of the mold in mind.

All the information on mold design is to be transferred into the electronic format. In other words, we are to introduce a single subject-matter information model encapsulating the glossary of specific objects' parameters, symbol and graphic relations between those parameters, workflows for mold design around the standard parts. Types of interdependencies arising during the mold design and manufacturing process, and the ways to harmonize specific objects and their forms, are outlined in figure 3 [6]. 


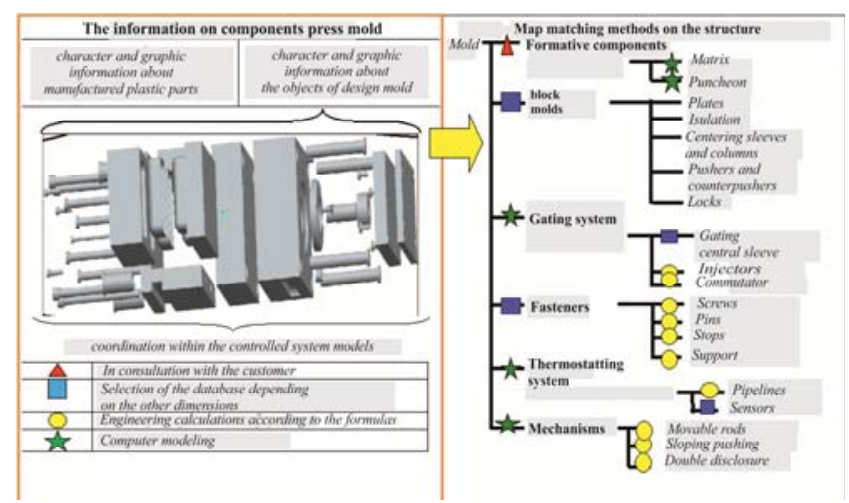

FIGURE III. MAP OPERATIONS IN THE DESIGN DECISIONS DURING THE CREATION OF THE MOLD

\section{ITERATIVE MANAGEMENT OF COMPLEX ITEMS DESIGN AND MANUFACTURING BASED ON A SET OF COMPUTER MODELS IN A UNIFIED IT ENVIRONMENT}

Iterative decision-making methods enable translation of customer's requirements into a completed mold form thanks to iterative transformation of previous decisions (or customer's requirements, at an early stage) using a set of pre-approved computer models.

A pre-defined set of computer models is highly likely to cater for comprehensive testing of all development options, making natural experiments unnecessary. Besides, each computer model is a standalone one, fully completed and independent (within the level of process formalization), enables practical mold elaboration and integration with other models based on the electronic knowledge base.

An electronic knowledge base is an open one, updated as needed. Thus, the electronic knowledge base and computer models are means of molds design and manufacturing knowledge accumulation and formalization into a single IT environment (figure 4) [7].

The main difference of this brand new approach compared to the legacy ones is that the 3D mold model, an information object elaborated at early stages of the design, is a virtual one for collective experimenting to find the ways to eradicate defects in a mold construction[8].

Mold information model accumulated as a part of the current project is a well-coordinated, pre-approved, interrelated, calculable and analyzable numeric information on the mold designed having geometric coordinates.

Using a set of computer models makes it much easier to design and manufacture molds; besides, it boasts many other advantages compared to the traditional design methods. First of all, a set of computer models enables you to:

- design a 3D model of a mold;

- find and match suitable mounting assemblies of the mold produced by different manufacturers;

- verify their feasibility, functional applicability and operability in advance;
- avoid internal discrepancies (collissions) within the structure of a mold.

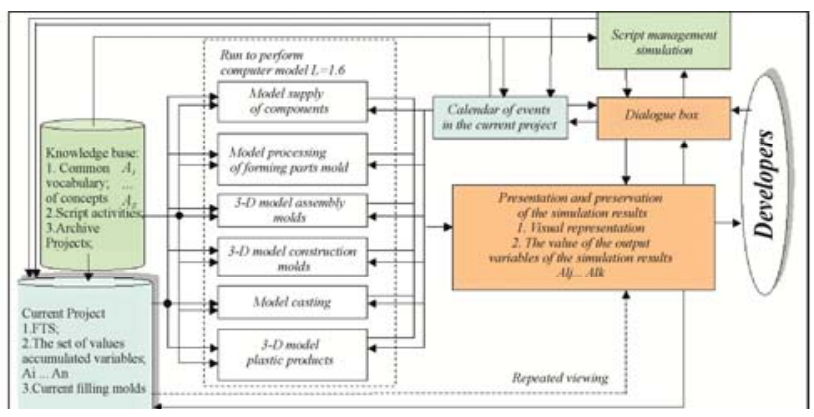

FIGURE IV. EXAMPLE THE STRUCTURE OF THE SIMULATION ENVIRONMENT FOR DESIGNING AND MANUFACTURING MOLDS BASED ON A SYSTEM OF COMPUTER MODELS)

It is important to note that, with an information model, it is possible to carry out most experiments on a virtual mold construction.

Verifications can be of different types, including but not limited to mathematical analysis (e.g., thermal and strength calculations, polymer flow analysis, etc.).

This technology is used to create a mold for car headlights (Lada) figure 5.

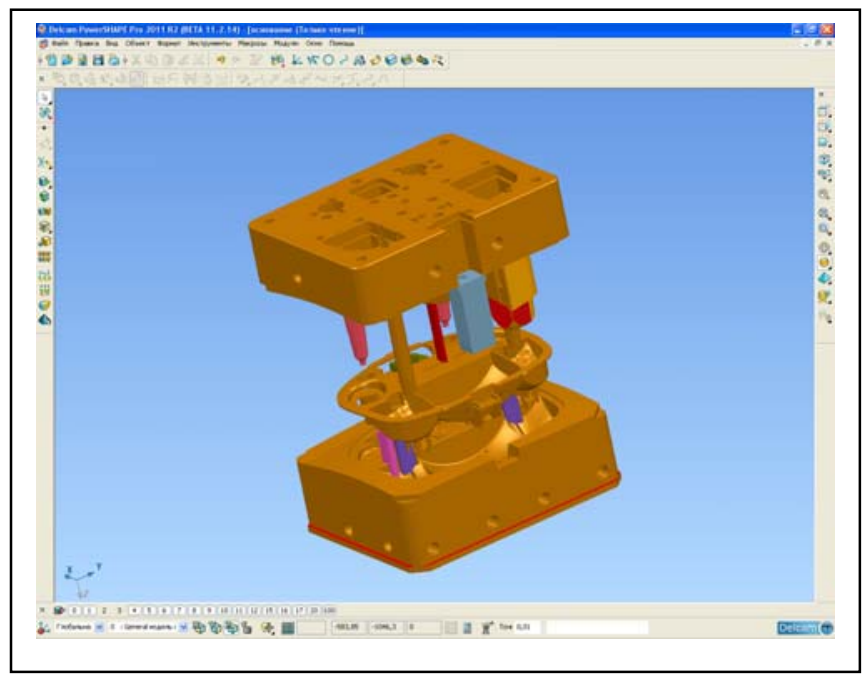

FIGURE V. A COMPUTER MODEL OF THE WORKING PART OF THE MOLD IN ASSEMBLY

\section{CONCLUSIONS}

Throughout the whole process of working on the assignment a pre-defined set of computer model is used to test the critical solutions fully.

Solution elaboration is characterized by both constant movement forward and return to the former dependencies for computer models. The key criteria to define the solution found 
as sustainable is that by the time the works are over, the number and the depth of project revisions from the ground-up diminish.

The process and the control means are getting more and more regulated throughout the implementation process, starting as "weak at the beginning" (creative phase) up to "strong in the end" (manufacturing stage).

The information within the mold model can be used externally as:

-operational 2D drawing documentation and 3D drawing views;

-spreadsheets, statements and specifications;

-utility delivery orders;

•engineering calculations results;

-files with data to be used for engineering calculations in other programs;

-presentational visualisation and animation models;

-sectional drawings and other snippets of the mold structure;

-STL-files for 3D printing;

-management programs for model creation (full or partial) using numeric control machines.

\section{REFERENCES}

[1] Evans.E. Domain-Driven Design Tackling Complexity in the Heart of Software: 2003, 359 c.

[2] Pernin K. Digital Prototyping - a new and unique approach to the design of plastic products // CAD / CAM / CAE Observer, 2010, №8, p. 32-33.

[3] Information modeling objects of industrial and civil construction (Design, construction, operation) autodeck, 2014

[4] Rybakov A.V., Kozhin M. V., Orlov A. A. Iteration control in the design and manufacture of complex products based on computer models in terms of informational and technological environment // Bulletin of computer and information technologies, 2009, №12, p. 21-28.

[5] Rybakov, A. V., Evdokimov S. A., Krasnov A. A. Create a system of automated support of information solutions in the design of tooling / V. A. Rybakov, S. A. Evdokimov, A. A. Krasnov . - M.: FGBOU VPO MSTU "STANKIN", 2013 . - 162 p.: ill.

[6] Rybakov, A. V., Evdokimov S. A., Krasnov A. A. The Use of traditional enterprise standards for constructing computer knowledge bases // journal of computer and information technologies, 2005, №2, p. 23-28.

[7] Rybakov, A. V., Krasnov A. A., P. I. Razinkov, Surpa A. N. Automation of the design process and production of tooling on the basis of a managed system of interconnected computer models (for example, molds for casting of plastics under pressure) $\mathrm{CAD} / \mathrm{CAM} / \mathrm{CAE}$ Observer, 2012, №5 (73), pp. 56-62.

[8] Grigoriev S., Kutin A., Turkin M. Advanced cnc programming methods for multi-axis precision machining Key Engineering Materials. 2014. T. 581. C. $478-484$ 